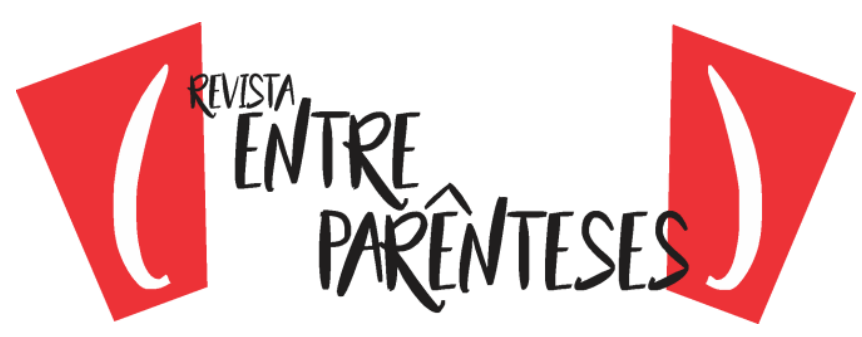

\title{
INTERTEXTUALIDADE CRÍTICA E HIPERTEXTO: UM ESTUDO DE CASO NO BLOG PRATELEIRA SEM FIM
}

\author{
Lucas Soboleswki FLORES ${ }^{1}$ \\ Universidade de Caxias do Sul (UCS) \\ (I.s.flores@outlook.com)
}

Resumo: Os blogs trazem uma estrutura de programação que possibilita a rápida atualização e aceita diferentes tipos de conteúdo nas publicações. Dentro desse contexto, dois conceitos importantes podem fazer parte de um texto para esse tipo de veículo comunicacional: a intertextualidade crítica e o hipertexto. Este artigo tem por objetivo apresentar como essas ideias se desenvolvem em uma publicação de resenha literária no blog Prateleira sem fim, estabelecendo relações entre a intertextualidade crítica e o hipertexto. Como principais resultados do estudo, identificou-se que existem características em comum entre essas modalidades de texto, de modo que uma pode complementar a outra.

Palavras-chave: Intertextualidade crítica; Hipertexto; Blogs

Abstract: Blogs have a programming structure that makes it possible to quickly update and accept different types of content in publications. Within this context, two important concepts may be part of a text for this type of communicational vehicle: critical intertextuality and hypertext. This paper aims to present how these ideas are developed in a literary review publication in the blog Prateleira sem fim, establishing relations between critical intertextuality and hypertext. With the main results of the study, it was identified that there are common characteristics between these modalities of text, so that one can complement the other.

Keywords: Critical intertextuality; Hypertext; Blogs

Resumen: Los blogs traen una estructura de programación que posibilita la rápida actualización y acepta diferentes tipos de contenido en las publicaciones. Dentro de ese contexto, dos conceptos importantes pueden formar parte de un texto para ese tipo de vehículo comunicacional: la intertextualidad crítica y el hipertexto. Este artículo tiene por objetivo presentar cómo esas ideas se desarrollan en una publicación de reseña literaria en el blog Prateleira sem fim, estableciendo relaciones entre la intertextualidad crítica y el hipertexto. Como principales resultados del estudio, se identificó que existen características en común entre esas modalidades de texto, de modo que una puede complementar la otra.

Palabras-clave: Intertextualidad crítica; Hipertexto; Blogs

\section{INTRODUÇÃO}

Os blogs trazem uma estrutura de programação que possibilita a atualização rápida e aceita diferentes tipos de conteúdo nas postagens, como

\footnotetext{
${ }^{1}$ Mestrando em Letras e Cultura (UCS), especialista em Comunicação Digital (UCS/PUCRS) e bacharel em Relações Públicas (UCS).
}

Revista (Entre Parênteses)

Número 7, Volume 1, 2018 - ISSN 2238-4502 


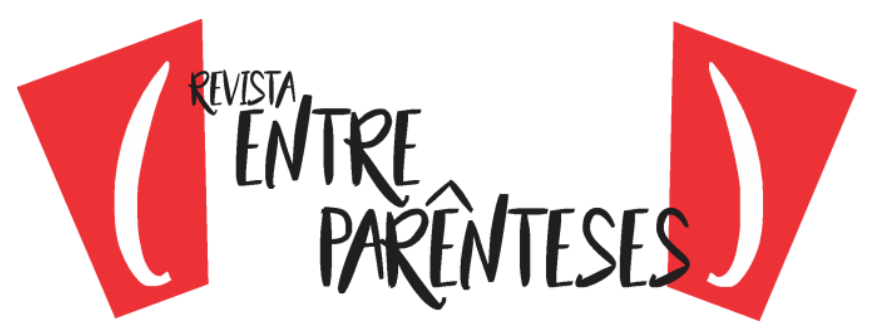

produções textuais, imagens, vídeos, áudios, entre outros. Tratam-se de espaços na internet de fácil domínio e com a possibilidade de conseguir seguidores específicos (ou não) sobre temas que geram informações e curiosidades. Ou seja, um blog é um ativo que pertence à proposta de seu administrador e seu domínio pertence somente a ele.

Amaral, Recuero e Montardo (2009, p. 31) veem os blogs como "[...] uma ferramenta capaz de gerar uma estrutura característica, constituída enquanto mídia, ou seja, enquanto ferramenta de comunicação mediada pelo computador."

Não restrito a um único tema, eles permitem que diversos assuntos possam ser discutidos, de modo que cada blogueiro pode se especializar e escrever sobre o assunto que domina ou tem mais interesse. Tais publicações podem ser rentabilizadas por meio de anúncios e outros tipos de publicidade, gerando renda para o produtor de conteúdo. Nas palavras de Oliveira:

A disponibilidade de centenas de ferramentas de postagem de blogs, muitas delas gratuitas, fez com que, rapidamente, homens e, especialmente, mulheres do mundo inteiro postassem suas vidas em formas de texto. Blogs, então, passam a desempenhar funções variadas, desde o modelo de filtro de notícias de Jorn Barger, passando por conteúdos jornalísticos, educacionais políticos e culturais ou até mesmo meros diários íntimos, no qual o blogueiro escreve, com detalhes, sobre o seu dia-a-dia. (OLIVEIRA, 2009, p. 56)

De acordo com a autora, vários são os conteúdos presentes em blogs, que vão desde temas jornalísticos, educacionais, políticos e culturais até diários íntimos. A literatura também está presente em muitos blogs e, em diversos momentos, se mistura com temas mais polêmicos como as críticas aos sistemas econômico, político e social do país. Um exemplo da diversidade de temas pode ser o que é mantido pela relações-públicas Taíla Quadros, de Caxias do Sul/RS, denominado de Prateleira sem fim $^{2}$. Trata-se de um espaço em que a blogueira compartilha suas experiências literárias, fazendo resenhas e comentários pessoais

\footnotetext{
2 O blog Prateleira sem fim pode ser acessado no seguinte endereço eletrônico: www.prateleirasemfim.com.br
} 


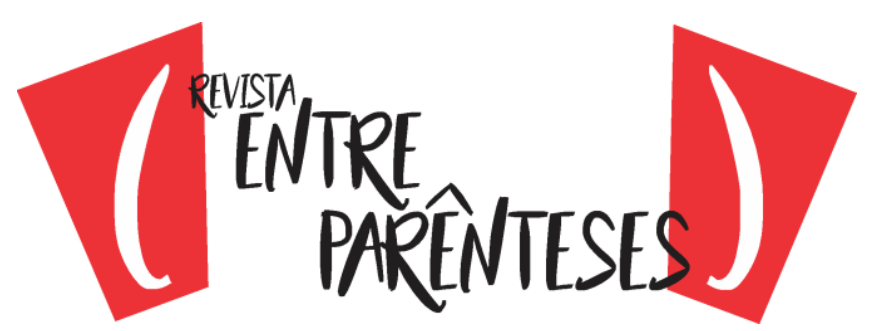

sobre as obras que leu. Além disso, esse blog contempla pensamentos, crônicas e outras modalidades textuais desenvolvidas pela autora.

Produzir textos para a web requer planejamento por parte dos blogueiros, assim como outras atividades de produção, intelectual ou não, necessitam de um roteiro que contemple várias fases, que vai desde o tipo de conteúdo até a periodicidade. Além disso, é preciso, entre outras coisas, que o produtor de conteúdo adote um formato de escrita que contenha atrativos para que o leitor se sinta orientado, confortável e com vontade de continuar a leitura. Nesse sentido, disserta Peçanha:

Quando lemos um artigo, por exemplo, não estamos olhando apenas as letras na tela à nossa frente. Nosso cérebro está trabalhando para entender aquele conteúdo, ativando estruturas mentais e criando uma 'voz interior', o que aumenta nossa atenção. Tudo isso gera um esforço cognitivo profundo, o que traz vantagens para a retenção de conteúdo. (PEÇANHA, 2017, p. 54)

A partir desse entendimento, trabalhar a intertextualidade e o hipertexto é importante para que o leitor de um blog tenha diferentes reações ao ler uma postagem, sobretudo quando se fala em resenhas literárias. Afinal, o objetivo principal dessa modalidade de conteúdo é fazer com que o leitor leia a resenha e, ao ler, vá em busca da obra resenhada.

Sobre a intertextualidade, Perrone-Moisés (1979) afirma que nesse processo não ocorre apenas a soma de textos, mas sim um fenômeno de absorção e transformação de um texto em outro texto. A partir dessa perspectiva, quando um blogueiro faz uma análise sobre um livro está aplicando a técnica da intertextualidade.

Assim sendo, este trabalho objetiva estabelecer relações entre a intertextualidade e o hipertexto - tipo de texto produzido para a internet comentando sobre como ambos os conceitos se desenvolvem no universo dos blogs. Para exemplificar essa realidade, foi utilizado o blog post "La tía Cristinaresenha", publicado no Prateleira sem fim. 


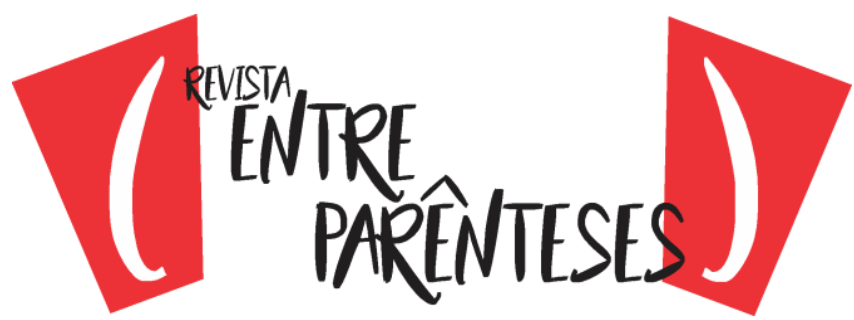

\section{INTERTEXTUALIDADE X HIPERTEXTO: RELAÇÕES ENTRE OS CONCEITOS}

Um intertexto nada mais é do que um texto que, em sua composição, faz referências ou dialoga com outros textos. Em sentido amplo, a intertextualidade pode assumir diferentes posturas, ser de caráter poético, como quando uma obra literária faz referências à outra ou de caráter crítico, quando se fazem análises de um outro conteúdo.

Já o hipertexto é uma forma de escrita em que o leitor não precisa seguir uma ordem linear, podendo optar por vários caminhos. Ao fazer uma leitura de um artigo publicado no Wikipédia, site de pesquisas que adota o formado de hipertexto, o internauta é guiado por um índice remissivo, de modo que, ao clicar em cada um dos intertítulos, é direcionado para uma parte em específico do texto sobre o tema pesquisado.

A intertextualidade, de acordo com Perrone-Moisés (1978), não é algo recente e acontece desde obras literárias muito antigas, que faziam referências a textos bíblicos ou de origem greco-latina. Na visão da autora:

O inter-relacionamento de discursos de diferentes épocas ou de diferentes áreas linguísticas não é novo, podemos mesmo dizer que ele caracteriza desde sempre a atividade poética. Em todos os tempos, o texto literário surgiu relacionado com outros textos anteriores ou contemporâneos, a literatura sempre nasceu da e na literatura. Basta lembrar as relações temáticas e formais de inúmeras grandes obras do passado com a Bíblia, com os textos greco-latinos, com as obras literárias imediatamente anteriores, que Ihes serviam de um modelo estrutural e de fonte de 'citações', personagens e situações (A Divina Comédia, Os Lusíadas, Dom Quixote, etc). (PERRONE-MOISÉS, 1978, p. 59)

Ainda, de acordo Perrone-Moisés (1979, p. 210), ao elencar suas observações empíricas sobre a intertextualidade crítica, a autora comenta que essa modalidade de escrita é "[...] declarada, ou seja, submetida a uma lei, enquanto a intertextualidade poética pode ser tácita (e a maior parte das vezes o é)." Ou seja, na modalidade crítica, o texto segue um padrão, com o uso de referências bibliográficas, aspas, entre outras condições que garantam uma postura submissa. Já a segunda supõe uma forma mais incontrolada do texto abrigado. 


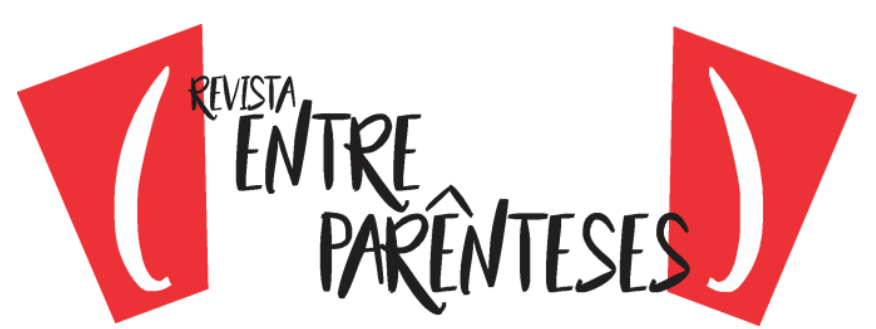

Para a autora, o que caracteriza o conteúdo crítico de um intertexto é a submissão e a argumentação sobre a extensão do que está posto. Em suas palavras:

Enquanto a estrutura do discurso poético engloba a dos textos estranhos que abriga, a estrutura do discurso crítico tradicional, pelo contrário, é englobada pela do texto indutor, que a modela e a situa em posição de filiação e de prolongamento. (PERRONEMOISÉS, 1979, p. 211)

Exemplos da intertextualidade crítica, tomando como base a definição de Perrone-Moisés (1979), podem ser encontrados no prefácio ou posfácio de um livro escrito por um convidado, seja por referência ou seja pela autoridade que exerce sobre o tema. Outro exemplo é quando um colunista de literatura de jornal ou revista escreve suas percepções sobre uma determinada obra e também quando um blogueiro desenvolve um texto comentando sobre um exemplar que fez a leitura.

$\mathrm{Na}$ contemporaneidade, época em que muitos dos relacionamentos e trocas ocorrem na internet, é comum que o intertexto também seja aplicado no conceito de transmídia. Gabriel (2010, p. 114), ao fazer uma análise sobre esse fenômeno, comenta que:

Desde os primórdios da televisão, por exemplo, é muito comum que uma notícia veiculada na TV num dia, seja discutida, no jornal, no outro. Matérias de revistas foram várias vezes propagadas para a TV, dando continuidade ao tema, mesmo que com abordagens distintas. (GABRIEL, 2010, p. 114)

Ou seja, temas abordados em veículos de comunicação são, muitas vezes, a extensão de algo já divulgado, quer por outros programas ou até mesmo por obras literárias. Essa prática caracteriza-se em trazer em relevo fatos e histórias que foram destaque, sobretudo pelo consumo das informações obtidas ou pela relevância - social, econômica ou política - do que foi narrado.

Por outro lado, um conteúdo caracterizado como intertextualidade também pode ser considerado uma narrativa transmidiática, uma vez que um livro impresso pode ser resenhado em um blog, no ambiente digital, como pode, 


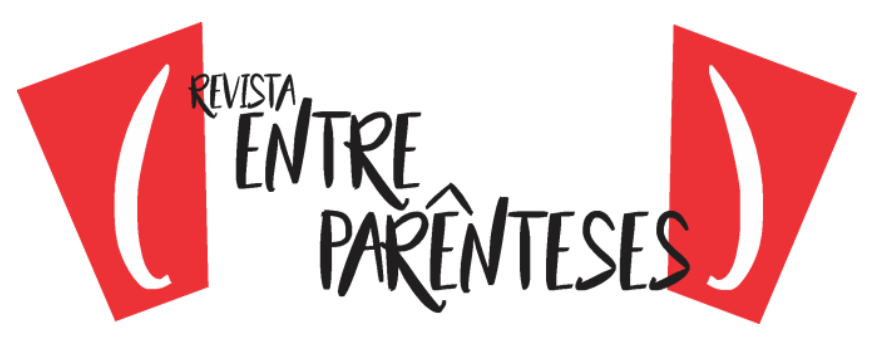

também, ter o seu conteúdo transformado em um filme, em uma série de TV, em um jogo de video game, entre outras situações.

O que diferencia o conteúdo intertextual publicado em um meio impresso do publicado em um meio digital é a possibilidade de ser desenvolvido um hipertexto, que de acordo com Lévy (2010, p. 114), é uma forma de texto "[...] constituído por nós (os elementos de informação, parágrafos, páginas, imagens, sequências musicais etc.) e por links entre esses nós, referências, notas, ponteiros, 'botões' indicando a passagem de um nó a outro".

A vantagem da leitura na web é que não precisa ser feita de maneira linear e a intertextualidade pode ser ainda mais desenvolvida, principalmente pela possibilidade de o autor incorporar vários elementos ao texto, como fotos, desenhos, vídeos, entre outros.

Sobre as diferenças entre a redação para web e a redação em veículos tradicionais impressos, Assad comenta:

O que difere a redação on-line, também chamada de webwriting, da impressa é a exigência que ela sofre de ser mais que um texto, pois na web ele só é mais uma parte de uma página. Ele pode estar relacionado a uma imagem ou até mesmo fazer parte dela, como é o caso do infográfico, mas acima de tudo é um formato de informação que precisa reter a atenção do usuário, que pode ser persuadido por um design criativo do site e esquecer-se do seu texto. (ASSAD, 2016, p. 66)

Peçanha (2017, p. 126) segue a mesma linha de raciocínio de Assad e comenta que um blog post "[...] precisa cumprir duas funções essenciais: atrair o público até ele e fazer com que, uma vez que o leitor já esteja no seu blog, ele fique lá o maior tempo possível." De acordo com a visão do autor, acredita-se que alguns fatores devem ser considerados ao se ter em mente que alguns leitores podem estabelecer certa fidelidade com o blog. Entre os fatores, podem estar a periodicidade dos posts e a postura do blogueiro, que pode ter uma ideologia ou modo de pensar que atraia um determinado público-alvo.

Outros fatores preponderantes, de acordo com os autores, são de natureza técnica, como as características do hipertexto, em que os elementos, 


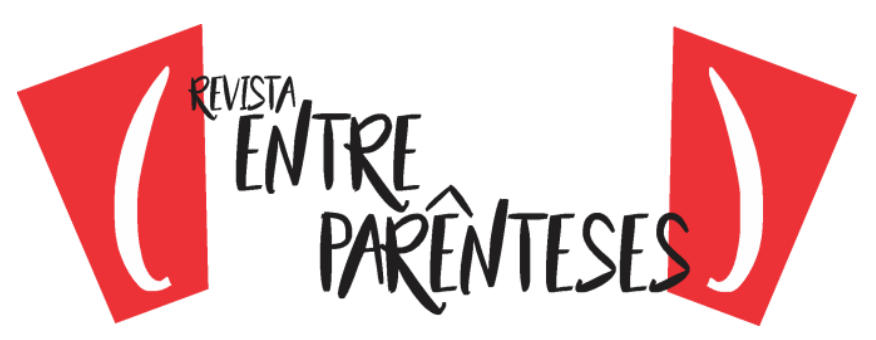

como: o título, a estrutura do post, a escaneabilidade, os parágrafos curtos, os intertítulos e os hiperlinks devem estar presentes no layout do texto.

Entre os elementos apontados, os hiperlinks são o que mais denotam características da intertextualidade em um hipertexto, uma vez que o leitor pode clicar nas palavras destacadas e ser direcionado para outras páginas, contento outros textos que podem complementar a leitura, como fontes de pesquisa dos dados citados e informações extras sobre determinado assunto. Esse recurso tende a ser benéfico para o leitor, pois permite uma navegação instantânea.

Sobre o uso de hiperlinks na redação de textos para a internet, Assad (2016, p. 67) comenta que eles "[...] devem funcionar como guias para direcionar o usuário a assuntos relacionados que podem complementar a informação do texto, criando uma rede de conexões".

Perrone-Moisés (1979) desenvolveu seus estudos sobre a intertextualidade crítica, na década de 1970, época em que o hipertexto ainda não tinha se desenvolvimento como no século XXI. O desenvolvimento da prática do hipertexto começou na década de 1990, com a ascensão da internet para uso pessoal e empresarial.

Mesmo assim, a autora já tinha uma visão de textos que conversam entre si, classificando as produções em texto analisado e texto analisante. Nas palavras da própria autora, a intertextualidade crítica:

Sempre se tratou de escrever um texto sobre outro texto, um texto que dialoga com o outro. Assim, mesmo no caso mais simples (evidentemente hipotético, como todas as $<<$ formas simples $>>$ ), há no discurso crítico um entrecruzar de dois textos, o texto analisado e o texto analisante. (PERRONE-MOISÉS, 1979, p. 210)

$\mathrm{Na}$ atualidade, é comum, ao se falar sobre uma obra literária ou outro texto qualquer, que o autor incorpore, em formato de hiperlinks, o texto analisado no texto analisante. Essa ideia pode ser melhor compreendida quando verificamos uma das boas práticas citadas por Assad (2016) para a redação na web. Para a autora, o uso de hiperlinks só deve ser feito "[...] ao longo de um texto quando 


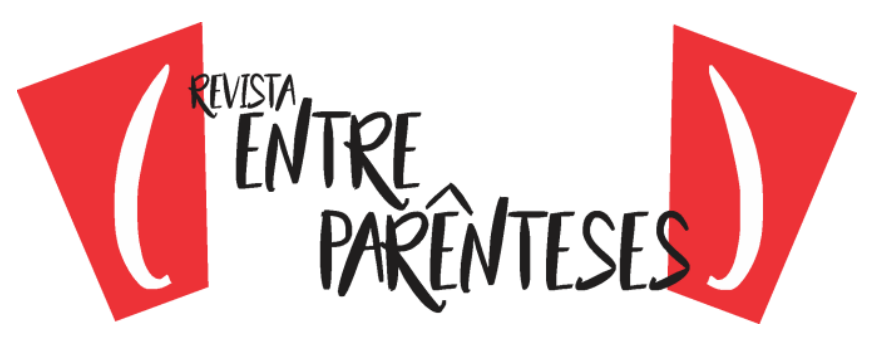

forem complementar o conteúdo, nunca quando possam abrir as portas para outra informação diferente da primeira" (ASSAD, 2016, p. 67).

De maneira geral, podemos dizer que existem diversas relações entre a intertextualidade e o hipertexto. A principal delas pode ser apontada como a fusão de dois ou mais textos em um só, pois, como aponta Nitrini (2000, p. 162-163): "Toda sequência está duplamente orientada: para o ato da reminiscência (evocação de uma outra escrita) e para o ato da somação (a transformação dessa escritura)".

A partir dessas observações, a seção seguinte traz a forma como a intertextualidade e o hipertexto ocorrem em uma publicação de resenha de uma obra literária no blog Prateleira sem fim.

\section{ANÁLISE DA INTERTEXTUALIDADE E DO HIPERTEXTO EM POST DO BLOG PLATELEIRA SEM FIM}

Para exemplificar a presença da intertextualidade crítica e do hipertexto em uma resenha literária publicada na internet, analisaremos o post denominado "La tía Cristina - resenha", publicado no dia 9 de janeiro de 2018 no blog Prateleira sem fim.

"La tía Cristina" é um dos contos da escritora mexicana Ángeles Mastretta, presente no livro Mujeres de ojos grandes, de 1990. Após fazer a leitura do texto, a blogueira Taíla Quadros publicou uma resenha com as percepções que teve da obra. A resenha caracteriza a ideia de intertextualidade, pois incorpora em seu texto analisante elementos do texto analisado, conforme a teoria defendida por Perrone-Moisés (1979). Isso pode ser verificado no fragmento do texto, publicado no Prateleira sem fim e apresentado, a seguir:

O conto fala da história da tia Cristina, uma jovem de 21 anos que estava 'perdendo' o tempo de se casar, como se dizia antigamente, e ia ficar para a tia. Porém, quando todos já tinham perdido as esperanças de que ela arrumaria um casamento, tia Cristina chega em casa dizendo que conheceu o homem da sua vida. Em seguida, recebe uma encomenda com um anel de noivado e uma carta com 


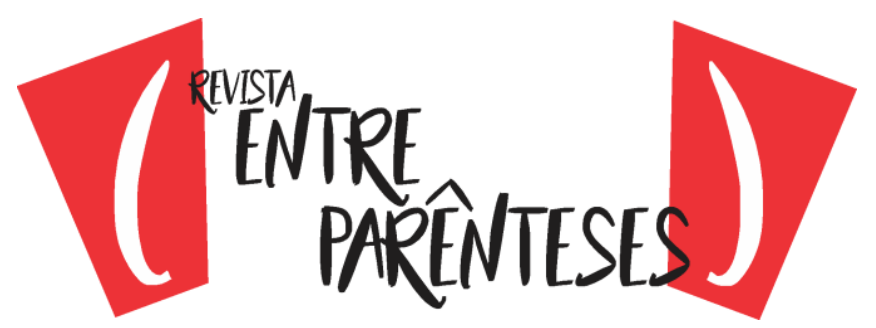

um pedido de casamento, entregue pelo amigo do homem misterioso, que inclusive estava indo para a Espanha e esperaria por ela lá para viverem juntos. (QUADROS, 2018, p. 1)

É possível observar que a autora do blog conta um resumo da história do conto, fazendo uso da intertextualidade, pois foi necessário ler e compreender o conto de Ángeles Mastretta para que o parágrafo fosse desenvolvido.

A continuidade da leitura da resenha, do referido blog, mostra que o texto assume um caráter crítico, indo ao encontro dessa classificação proposta por Perrone-Moisés quando diz:

O crítico é alguém que entra em propriedade alheia, que a usufrui durante algum tempo, e isso pressupõe o respeito por certas regras, sendo a mais elementar o reconhecimento dos limites da propriedade, dos direitos do proprietário e dos deveres do não proprietário. (PERRONE-MOISÉS, 1979, p. 211)

Essa constatação proposta por Perrone-Moisés pode ser observada na resenha desenvolvida no blog Prateleira sem fim, quando a autora tece comentários pessoais acerca da leitura:

Por mais que tenha lido em outro idioma (toda poliglota ela), achei a leitura fluida e o estilo do conto bem jovem e divertido até, não são piadas, mas é que o tom da leitura é leve e inteligente. Mais um preconceito literário a ser quebrado, quando achamos que autores que não conhecemos ou com estilos diferentes do que estamos acostumados não são bons. Sempre vale a pena experimentar e se aventurar na leitura e na vida. São tantas surpresas que o caminho nos reserva, não é mesmo? (QUADROS, 2018, p. 1)

De maneira respeitosa aos direitos da autora Ángeles Mastretta, a blogueira Taíla Quadros comenta sobre o estilo da escrita, a maneira como o texto é redigido no conto, entre outros aspectos. Essa análise pode ser considerada, de acordo com Perrone-Moisés (1979), um intertexto com teor crítico.

Outra característica proposta por Perrone-Moisés para a intertextualidade crítica é a presença da identificação do autor do texto analisante, deixando claro para o leitor que se trata de uma obra que fala de outra obra. Além disso, também fica claro para o leitor que a análise crítica é uma opinião pessoal 


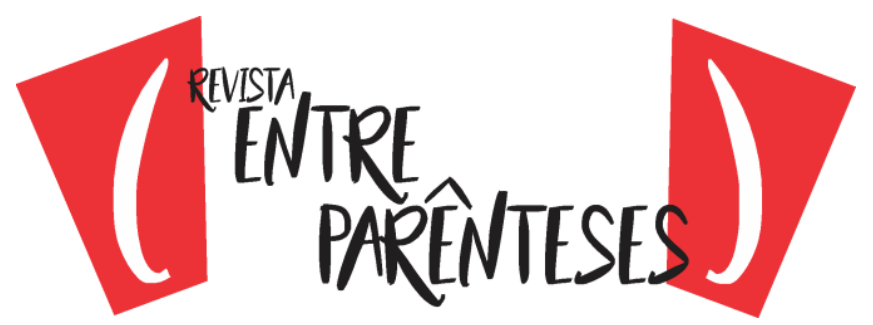

do autor daquele texto acerca do que foi dito na obra analisada. Nas palavras da autora:

O crítico declara (confessa) que escreve sobre uma ou várias obras; o nome do autor-tutor e o da obra-assunto figuram frequentemente no próprio título do livro ou do artigo crítico; senão, hão de aparecer como referências explícitas desde o começo do texto crítico, no seu discurso ou em notas. (PERRONE-MOISÉS, 1979 , p. 210-211)

No blog Prateleira sem fim, a declaração de autoria da obra aparece em dois locais diferentes, conforme visto na figura 1.

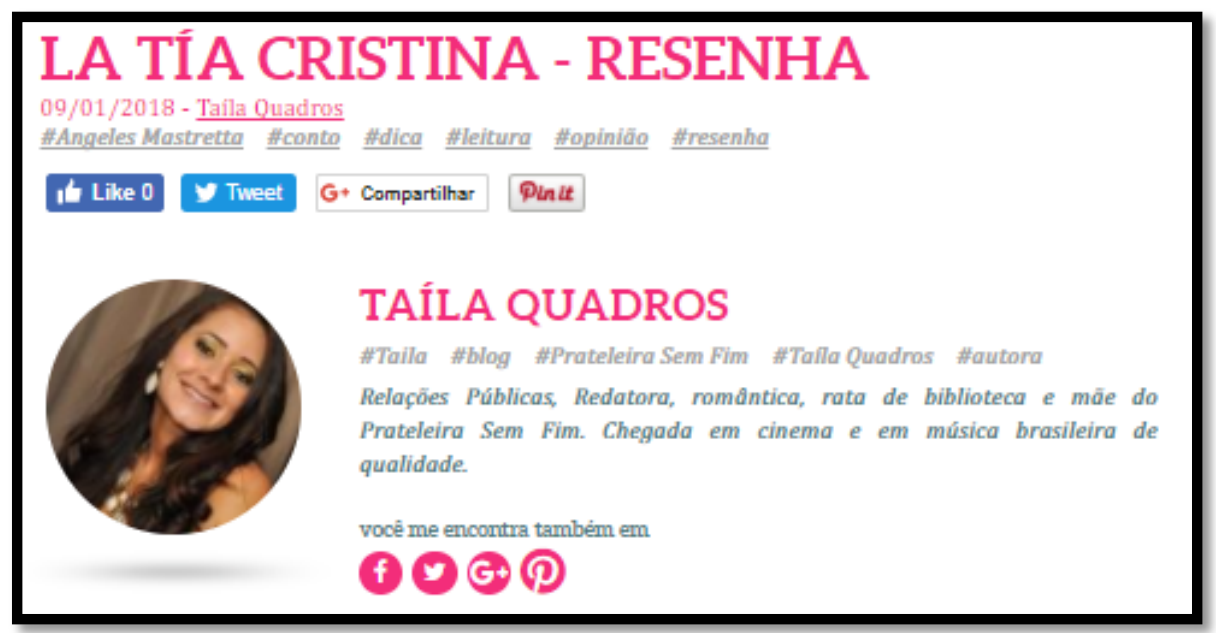

FIGURA 1 - DECLARAÇÕES DE AUTORIA DO TEXTO "LA TÍA CRISTINA - RESENHA"

Fonte: montagem desenvolvida pelo autor a partir da publicação no blog Prateleira sem fim.

É possível verificar o nome da autora logo embaixo do título da resenha, bem como no rodapé do texto, onde além do nome se encontra uma fotografia e informações gerais da blogueira. Outro indicativo do teor crítico do texto é a hashtag ${ }^{3}$ opinião, também localizada no cabeçalho.

No que se refere ao hipertexto, que conforme defendido anteriormente, representa um tipo de intertextualidade, também há elementos presentes na

\footnotetext{
${ }^{3}$ Palavra-chave antecedida pela cerquilha (\#) que identifica a temática do conteúdo que está sendo compartilhado nas mídias sociais.
} 


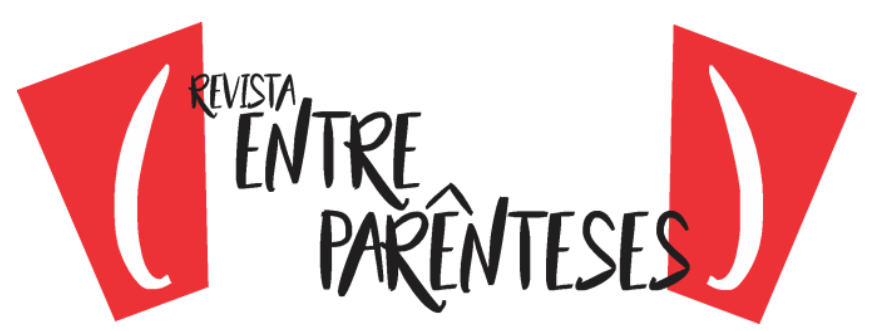

publicação da resenha do conto de Ángeles Mastretta. A principal característica que pode ser observada são os hiperlinks.

Na Figura 2, a seguir, vemos dois exemplos da prática de link building ${ }^{4}$ no conteúdo produzido pela blogueira Taíla Quadros. Percebe-se que houve o cuidado em deixar os links que direcionam para outras páginas na cor rosa, se destacando do restante do texto que é escrito em um tom de cinza. Isso vai ao encontro do que propõe Assad (2016, p. 67-68) ao orientar sobre essa prática: "Quando utilizar links de outros sites, deixe isso claro para o usuário, pois ele pode se perder e não conseguir retornar à sua página".

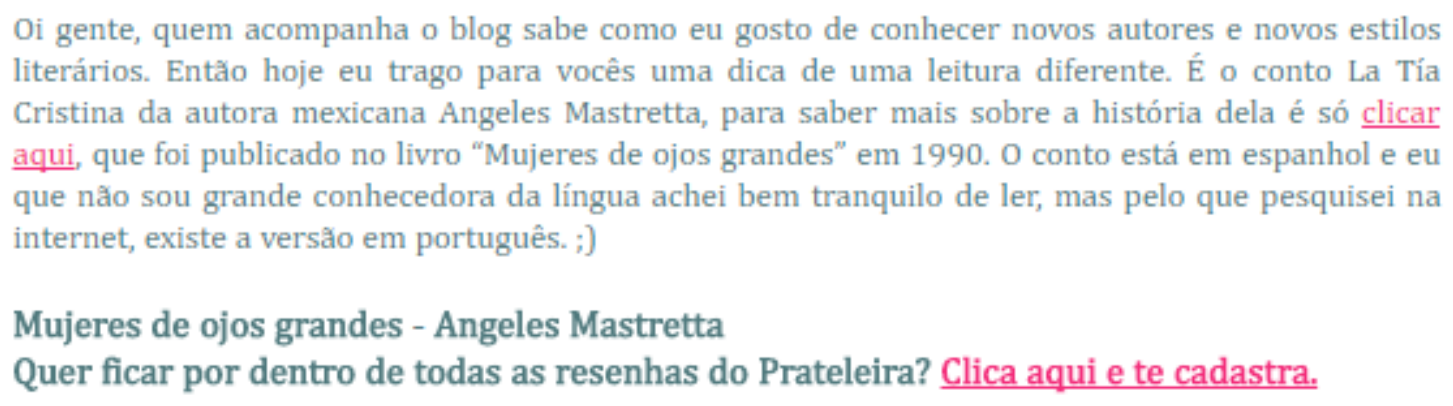

Oi gente, quem acompanha o blog sabe como eu gosto de conhecer novos autores e novos estilos literários. Então hoje eu trago para vocês uma dica de uma leitura diferente. É o conto La Tía Cristina da autora mexicana Angeles Mastretta, para saber mais sobre a história dela é só clicar aqui, que foi publicado no livro "Mujeres de ojos grandes" em 1990. 0 conto está em espanhol e eu que nåo sou grande conhecedora da língua achei bem tranquilo de ler, mas pelo que pesquisei na internet, existe a versåo em português. ;)

Mujeres de ojos grandes - Angeles Mastretta

Quer ficar por dentro de todas as resenhas do Prateleira? Clica aqui e te cadastra.

\section{FIGURA 2 - ELEMENTOS DO HIPERTEXTO EM POST DO BLOG PRATELEIRA SEM FIM}

Fonte: montagem desenvolvida pelo autor a partir da publicação no blog Prateleira sem fim.

O primeiro dos links inseridos no blog de Taíla direciona para o artigo "Ángeles Mastretta: la mujer y su obra", um texto com informações sobre a escritora da obra resenhada, escrito por Carlos M. Coria-Sanchez. Desse modo, quando uma pessoa que está lendo a publicação do blog, gosta de saber sobre o conto com a história de Tia Cristina e deseja obter mais informações sobre os demais livros publicados pela autora, bem como sobre a sua trajetória de vida, de modo geral, pode ser levada até um texto, publicado em outro meio digital, que contém essas informações.

O segundo hiperlink direciona o leitor para uma página de cadastro de

\footnotetext{
${ }^{4}$ Processo de inserir links de outro site em uma publicação, gerando relevância para o conteúdo que está sendo indicado.
} 


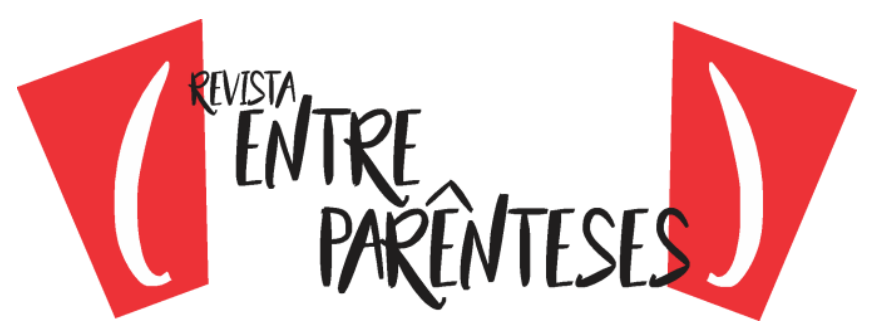

newsletter ${ }^{5}$, para que a blogueira possa incluí-lo em sua lista de contatos e enviar informações por e-mail quando novos posts forem publicados no blog.

O hipertexto, segundo Gabriel (2010), é uma narrativa que permite a convergência midiática, ou seja, a possibilidade de que uma mídia interaja com outra, em um mesmo local. Isso ocorre na resenha publicada no blog Prateleira sem fim, que tem um plug-in ${ }^{6}$ que interliga o blog à rede social Facebook, de modo que os leitores, quando acessam aos textos publicados possam deixar seus comentários sobre a publicação, por meio de seu perfil nessa mídia, conforme mostra a figura 3 , a seguir.

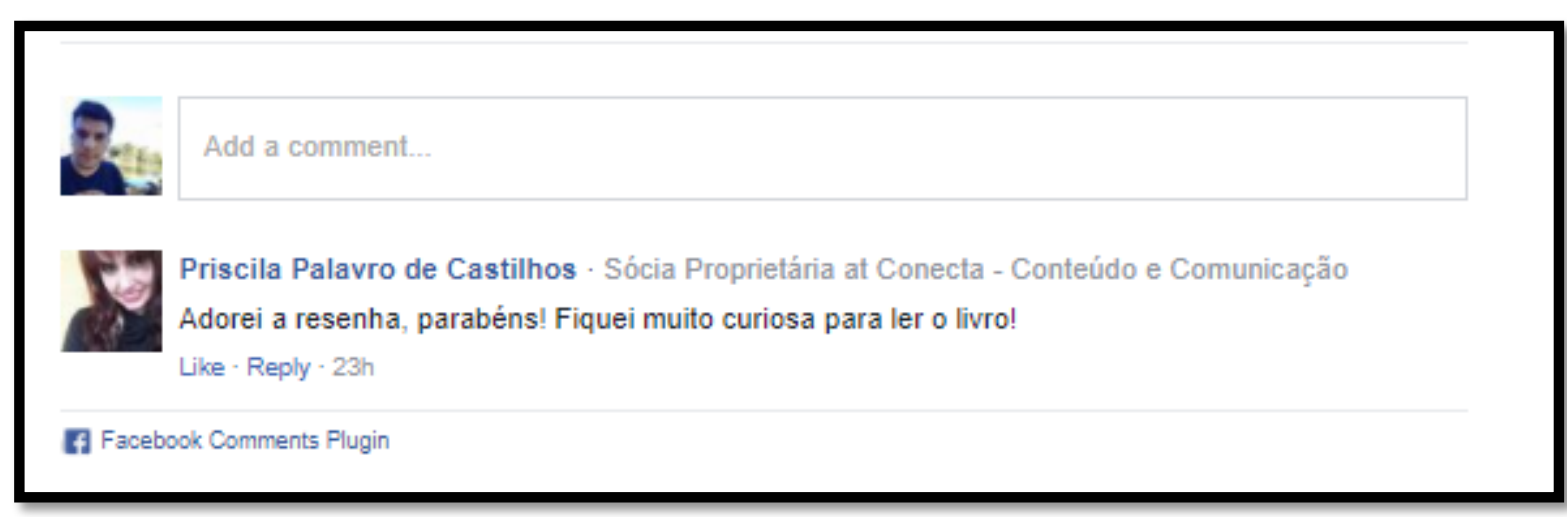

\section{FIGURA 3 - EXEMPLO DE COMENTÁRIO DEIXADO NO POST ANALISADO DO BLOG PRATELEIRA SEM FIM}

Fonte: montagem desenvolvida pelo autor a partir da publicação no blog Prateleira sem fim.

Os comentários deixados pelos leitores em um blog também podem caracterizar a intertextualidade crítica e o hipertexto, pois apesar de curtos, eles representam a opinião de alguém sobre um texto já existente. Eles têm tanta importância que, na visão de Recuero (2010, p. 119-120), são “[...] muito valorizados pelos blogueiros e, frequentemente, um fator motivacional relevante

\footnotetext{
${ }^{5}$ Boletim informativo enviado por empresas ou pessoas físicas que desejam informar uma grande quantidade de pessoas sobre um acontecimento ou até mesmo divulgar uma informação que seja de interesse do público-alvo.

${ }^{6}$ Programa instalado no código de programação de um site ou blog, que permite a criação de recursos que não estão presentes no HTML principal.
} 
para a continuidade do blog."

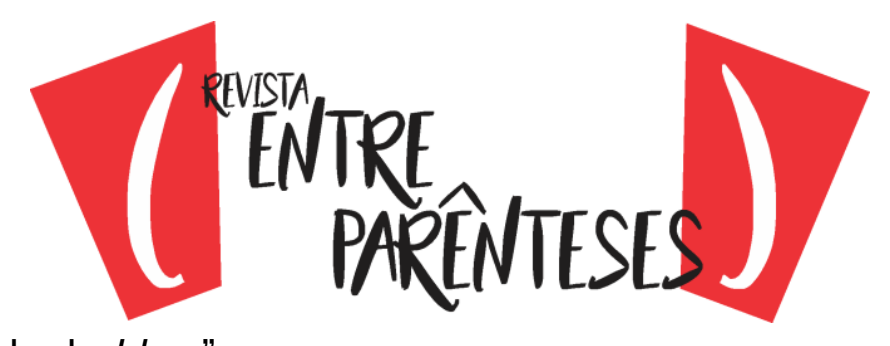

Conforme observado, é evidente que os blog posts apresentam na composição de seu conteúdo os elementos principais da intertextualidade crítica e também do hipertexto. A análise da resenha do conto da escritora mexicana Ángeles Mastretta nos mostra que um conceito tão antigo como a intertextualidade sobrevive na contemporaneidade, ganhando ainda mais força e formas de acontecer, uma vez que a internet oferece muitas possibilidades de inclusão de conteúdos em outros conteúdos, bem como de interatividade entre escritores e leitores.

\section{CONSIDERAÇÕES FINAIS}

Em suas pesquisas, Perrone-Moisés (1979) trouxe como perspectivas de intertextualidade as obras dos autores: Blanchot, Butor e Barthes. Tais análises fizeram com que a pesquisadora concluísse que a intertextualidade crítica é algo que ultrapassa as citações, de modo que também se desenvolvem por meio da mistura da escrita, da disseminação e da colagem.

A pesquisadora conclui um de seus artigos sobre essa temática questionando sobre a perda de uma especificidade discursiva que permite dar a um discurso o nome de crítico. Isso é muito relevante, principalmente nos tempos atuais, em que há muita facilidade para que alguém crie páginas na internet e disserte a sua opinião sobre assuntos diversos.

Por esse motivo é importante que, ao lermos ou escrevermos um texto de caráter crítico, como a resenha de um livro, tenhamos a responsabilidade de não apenas reeditar aquilo que já foi dito ou escrito por outra pessoa, mas sim registrar a nossa visão sobre o assunto, trazendo mais contribuições sobre o tema abordado.

A essa continuidade de informações que se formam sobre um texto, Perrone-Moisés chama de obra inacabada. A autora comenta que:

Para que a crítica não seja uma simples reprodução, é preciso que considere a obra, as obras, como imperfeitas (no sentido de 


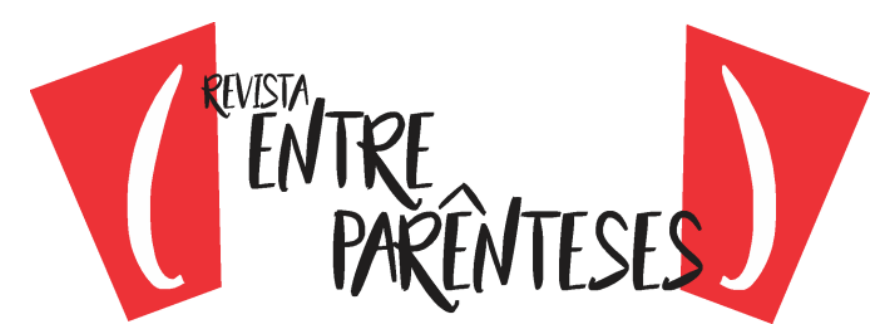

inacabadas, como se diz das capelas da Batalha, em Portugal, que são <<imperfeitas>>) (PERRONE-MOISÉS, 1979, p. 217)

Atualmente, boa parte da produção de textos críticos se aloja na internet. O meio eletrônico é rico em termos de variabilidade de ferramentas disponíveis, pois auxilia no dinamismo e no processo de comunicação, cada vez mais rápido. Graças a esse avanço tecnológico, é possível que se realizem várias atividades em tempo real, porém é preciso ter ainda mais cuidado, seja como escritor seja como leitor, pois se a intertextualidade for aplicada, deve-se ter 0 cuidado de verificar a qualidade daquilo que está sendo dito, descartando o plágio de ideias ou outras situações de má-fé que abusem de direitos autorais ou intelectuais de terceiros.

Coincidência ou não, os robôs que fazem o ranqueamento das páginas do Google, maior site de pesquisas do mundo, exigem que as produções publicadas na internet tenham qualidade para alcançar um resultado privilegiado nas buscas, ou seja, para ocupar as primeiras posições de maneira orgânica, sem que para isso seja feito pagamentos para a empresa detentora do site. A essa exigência de qualidade, é dado o nome de relevância, que, de acordo com Gabriel (2010, p. 354), "[...] não está associada a palavras-chave, e sim à importância geral que uma página tem na web".

Isso comprova mais uma vez a relação entre intertextualidade crítica e hipertexto, pois os textos publicados na internet devem ter qualidade para adquirirem relevância, do mesmo modo que a intertextualidade precisa ter qualidade para não se tornar efêmera.

Ao fazer a análise dos conceitos de intertextualidade crítica e hipertexto na resenha do conto sobre a história de Tia Cristina no blog Prateleira sem fim, foi possível perceber que ambos os conceitos convergem em um mesmo espaço e fazem parte de um mesmo universo. Além disso, também nota-se que a intertextualidade e hipertexto contribuem para a formação cultural dos leitores do blog, pois pessoas que não leram o conto poderão se interessar por essa obra e sua autora, bem como pessoas que já o leram, poderão conhecer a visão que a blogueira tem sobre o assunto abordado, deixar comentários e trocar opiniões com 


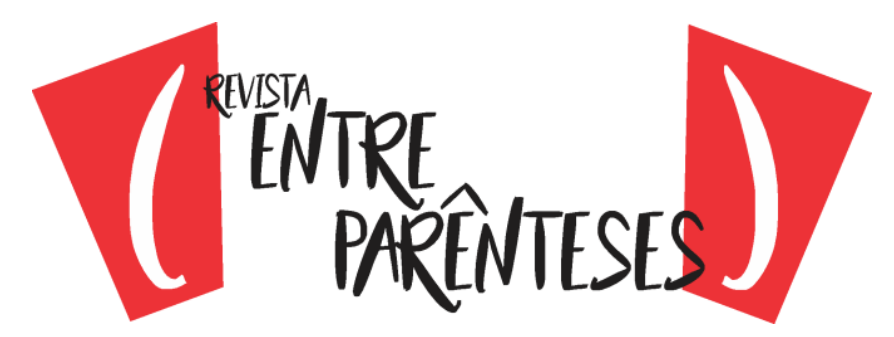

outros leitores naquele espaço, contribuindo para a formação da obra inacabada ou imperfeita.

\section{Referências}

AMARAL, A.; RECUERO, R. e MONTARDO, S. P. Blogs: mapeando um objeto. IN: AMARAL, A.; RECUERO, R. e MONTARDO, S. P. (Orgs.) Blogs.com: estudos sobre blogs e comunicação. São Paulo: Momento Editorial, 2009.

ASSAD, N. Marketing de conteúdo: como fazer sua empresa decolar no meio digital. São Paulo: Atlas, 2016.

CORIA-SANCHEZ,C. Ángeles Mastretta: la mujer y su obra. Repertorio de ensayistas y filósofos. 1999. Disponível em: < https://www.ensayistas.org/filosofos/mexico/mastretta/introd.htm> Acesso em 11 jan. 2018.

GABRIEL, M. Marketing na era digital: conceitos, plataformas e estratégias. São Paulo: Novatec, 2010.

LÉVY, P. Cibercultura. 2. ed. São Paulo: Editora 34, 2000.

NITRINI, S. Literatura comparada: história, teoria e crítica. 2 ed. São Paulo: Editora da Universidade de São Paulo, 2000.

OLIVEIRA, R. O ciberespaço e a escrita de si na contemporaneidade: repete o velho, o novo blog? IN: AMARAL, A.; RECUERO, R. e MONTARDO, S. P. (Orgs.) Blogs.com: estudos sobre blogs e comunicação. São Paulo: Momento Editorial, 2009.

PEÇANHA, V. Obrigado pelo marketing: um guia completo de como encantar pessoas e gerar negócios utilizando o marketing de conteúdo. São Paulo: Benvirá, 2017.

PERRONE-MOISÉS, L. Texto, crítica, escritura. São Paulo: Ática, 1978.

A intertextualidade crítica. IN: Poétique: revista de teoria e análise literária - intertextualidades. Coimbra: Livraria Almedina, 1979.

QUADROS, T. La tía Cristina - resenha. Prateleira sem fim. 9 jan, 2018. Disponível em: <https://www.prateleirasemfim.com.br/posts/livros/la-tia-cristinaresenha> Acesso em: 10 jan. 2018. 


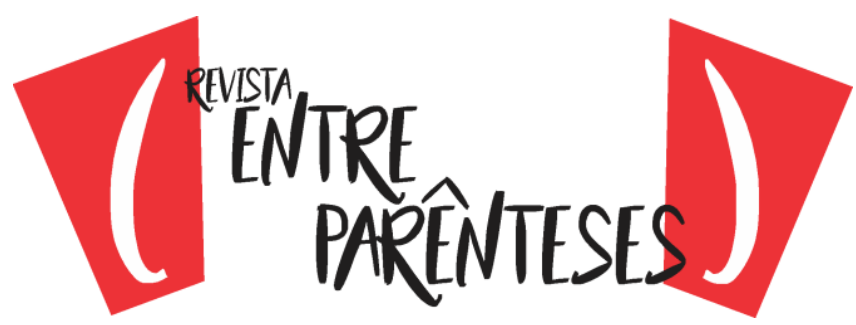

RECUERO, R. Fluxos de informação e capital social nos weblogs: um estudo de caso na blogosfera brasileira. IN: STEFFEN, César; POZENATO, Kenia (Orgs.) Mídia, cultura e contemporaneidade: análises e angulações. Caxias do Sul, RS: Educs, 2010.

Recebido em 04/04/2018.

Aceito em 18/08/2018. 